\title{
GIS-MAPPING OF THE ENVIRONMENTAL IMPACTS OF ROAD TRANSPORT IN RUSSIA
}

\author{
T.S. Nokelaynen* \\ *M.V. Lomonosov Moscow State University, Geographical Faculty \\ Vorob'ievy Gory, Moscow, Russia,nokelta@geogr.msu.su
}

\begin{abstract}
Road transport takes one of the leading places in pollution of the natural environment. Therefore, it is highly important to monitor and analyse the environmental impacts of road transport on the county scale. For this purpose the thematic ecological database was developed for the territory of Russia and the digital map of the environmental impacts of road transport was created on a scale of 1:30000 000.

The map consists of two thematic layers representing linear and territorial pollution from road transport. The linear pollution along the motorways is accessed according to the traffic intensity and the types of the cargos transported on the routes. The territorial pollution is characterised by the density of motorways, calculated based on the fine-scale cartographic materials and shown using isolines and layer coloring techniques. The conducted research enabled to define the priority regions of Russia requiring measures for an improvement of the transport and ecological conditions.
\end{abstract}

Keywords: GIS, mapping, road, transport, traffic, environtment, pollution, natura, Russia.

Nowadays, road transport plays one of the leading roles in the pollution of the environment. It determines the current ecological status throughout Russia, accounting for about $90 \%$ of the total volume of toxic matter produced by all types of transport.

Pollutants enter surface water reservoirs and groundwater, accumulate in soil, and influence harmfully plants and animals, as well as human health. Road construction requires abstraction of lands and leads to distortion of natural landscapes. Noise pollution of adjacent territories is also considered as one of the negative effects of road traffic on the environment.

Road transport is the most dynamic and rapidly developing out of all the types of transports. About $70 \%$ of all the transported cargoes and $60 \%$ of passengers are carried by motor cars in Russia. The acuteness of the problem 'Automobile-biosphere' (which obtained the global character already) is caused first of all by an increase in the number of vehicles. The volumes of emissions in the country as a whole depend directly on the number of cars. At present, the total number of automobiles in Russia is 48 millions, including more than 41 millions of light cars, about 6 millions of lorries and 0.8 million of autobuses [6].

That is why it is highly important to develop the specialized database on the environmental impacts of road transport which can serve as a tool for a detailed ecological assessment and monitoring.

This work became part of the project on modelling of the modern transport network of Russia and of the perspectives of its future development. In the ArcGIS environment a spatial database covering various types of transport was created in order to build a series of thematic maps [2, 3].

Under the framework of this research all the required information on road transport pollution was collected and structured in a GIS database, which enabled to create a series of specialized maps on the environmental impacts of road transport in Russia. This information contained characteristics of:

- local pollution in settlements;

- linear pollution along motorways;

- territorial pollution characterized by the density of motorways.

The most considerable is the local pollution in settlements and territories around them. In the large towns of Russia (such as Moscow, Saint-Petersburg, Krasnodar, Yekaterinburg, Ufa, Omsk, etc.) the share of automobile emissions is comparable with pollution caused by industrial plants. The contribution of automobile transport into total pollution of atmosphere in towns with less developed industry is greater in percentage and reaches $80-90 \%$ (Nalchik, Yakutsk, Makhachkala, Armavir, Elista, Gorno-Altaisk) [4].

Automobile exhaust gases contain about two hundred substances, most of them are toxic. The exhausts of spark ignition engines contain mostly carbon oxides, hydrocarbons and nitrogen oxides, and exhausts of diesel engines - nitrogen oxides and soot.

The main reason of unfavorable influence of automobile transport on the environment is the low technological level of vehicles and the absence of adequate systems of neutralization of exhausted gases. In Russia, the ecological standards for toxic matter content in exhausted gases are comparatively low and experience little change through the last thirty years.

The information on local pollution was summarized by the volumes of exhaust emissions into the atmosphere of towns according to following levels: more than $800000 ; 100000-200000$; 50 000-100 000; 20 000-50 000; $10000-20000$; and less than 10000 tons per year.

The levels of linear pollution along motorways can be assessed according to a set of indicators. The main one is the traffic intensity along the roads. The critical transportation load which triggers the pollution of soils and air is approximately 700-800 cars a day. The degree of pollution is influenced also by the types of cargoes transported and by the presence of polluting agents in them (coal, ore, mineral oil and construction materials).

The 300-meter wide strip along motorways experiences soil pollution by compounds of lead, zinc, cadmium, chromium and vanadium. There is a direct connection between the traffic intensity and the total amount of 
heavy metals deposited at the adjacent territory. The heavy metal content in soils and vegetation cover along the traffic flow (within the strip up to 10 meters) is 10-20 times higher than the reference values and it decreases almost twice at the distance of 120 meters.

The degree of technical equipment of roads defines their traffic load. For example, total volumes of emissions at highways are 12 times higher than at local roads. The share of paved roads characterizes the seasonal differences in the traffic intensity and therefore defines the fluctuations in emissions. The abrupt decrease in the traffic flow on the unpaved roads is observed in autumn and spring. Generally, the maximum traffic load is observed during the harvest season.

The ratio between lorries, motor cars and buses on roads with different cover types and at different parts of the roads influences the emission amounts. Light motor cars emit 3.5-4.5 times less combustion products than lorries.

The road sections near the settlements experience the increase in emissions in comparison to the average values. Usually, the amounts of exhausts increase near the region capitals, railroad stations, etc.

The noise level along the motorways depends on the traffic load, flow structure, road conditions and the construction types. The value $55 \mathrm{~dB}$ can be considered as the threshold level to define the presence of noise pollution and the level of $70 \mathrm{~dB}$ is considered as disturbing.

The territorial pollution is controlled by the level of transport network development. The density of motorway network can serve as an indicator of a negative territorial impact of the road transport on the environment.

The map of the influence of road transport on the environment in Russia (fig.1) is aimed to represent the linear pollution along motorways and territorial pollution caused by the transport networks.

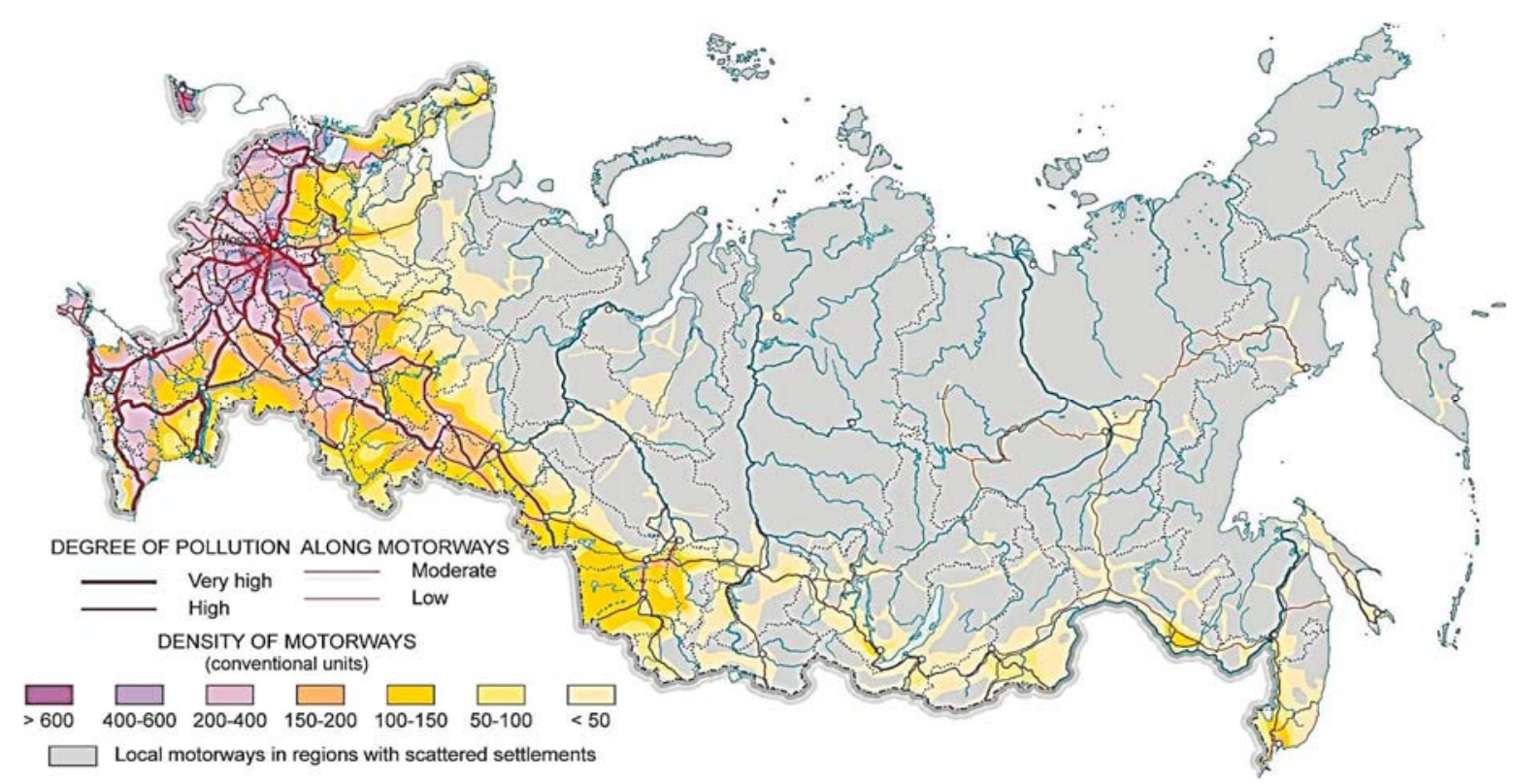

Fig. 1. The Influence of Road Transport on the Environment in Russia

The principal assessment criteria of the degree of pollution along motorways are the intensity of car traffic and types of cargoes transported. According to that, four levels of road transport pollution introduced by heavy metals, exhaust gases, transported cargoes, garbage and dust are distinguished.

The federal motorways with the traffic intensity of 7000 to 20000 cars per day in both directions are considered to have a very high pollution level. The high linear pollution level is typical for all the federal motorways with traffic intensity from 3000 to 7000 cars per day, as well as for the local roads, which are used for transportation of mining industry products. The federal motorways with the traffic intensity from 1000 to 3000 cars a day are considered as moderately polluted. The federal or local motorways at less developed territories with traffic intensity less than 1000 cars per day can be characterized by a low degree of pollution.

The territorial pollution is reflected on the map by the density of motorways depicted using isolines and layer coloring designed for eight bands. For this purpose the road network density index was calculated based on the fine-scale cartographic materials using the probabilistic statistical methods of determining the length of roads [5, 1].

Isolines of the road network density were created using the interpolation method in accordance with the discrete event theory and taking into account the geographical peculiarities of the network configuration. The resulting quantitative characteristics of isolines allowed to produce a reliable zoning of the territory according to the degree of road transport influence on the environment.

Usually, the maps of density of transport routes are compiled based on the statistical information with the use of the cartogram method. This method leads to a considerable generalization and schematization of a territory. On the contrary, the proposed methodology allows creating a more detailed map which is closer to the real distribu- 
tion of the transportation network in Russia.

The compiled 1:30 000000 scale map of the Russian Federation clearly shows the general patterns and territorial characteristics of traffic load, highlighting the level of transport development and environmental sustainability in different regions of Russia. It gives the opportunity to compare the regions with each other and to define of priority areas, which require urgent measures in order to improve the environmental situation aggravated by the road transport.

\section{REFERENCES}

1.Atlas Roads: Russia, CIS and Baltic States. Roskartografia, - Omsk, - 2013. - 272 p. (In Russian).

2. Belousov S.K., Nokelaynen T.S. GIS-Mapping of the Air Transport Development Dynamics in Russia. In: Proceedings of the International Conference InterCarto-InterGis 15 "Sustainable Development of Territories: GIS Theory and Practice". Perm (Russia), Gent (Belgium), June 29-July 05, - 2009. - Perm, - 2009. - Volume 1. - pp.29-36.

3.Belousov S.K., Nokelaynen T.S. GIS-Mapping of the Railway Transport Development in Russia. In: Proceedings of the International Conference InterCarto-InterGis-16 'Sustainable Development of Territories: GIS Theory and Practice'. Rostov-on-Don (Russia), Salzburg (Austria), July 03-04. - 2010. - Rostov-on-Don. - 2010. - pp.25-30.

4.Ecological Atlas of Russia. ZAO 'Karta'. - 2002. - 128 p.

5.Russia. Main Road Atlas. S.Petersburg, ZAO 'Karta'. - 2008. - 580 p.

6.Transport and communication in Russia: Statistical book/ Rosstat - Moscow. - 2014. - $114 \mathrm{p}$.

7.http:// www.gks.ru - The Official Website of the Federal State Statistics Service of Russian Federation. 